\title{
Demographic, Clinical and Laboratory Characteristics of Adult-Onset Minimal Change Disease in Turkey: Turkish Society of Nephrology- Glomerular Diseases (TSN-GOLD) Working Group
}

Zeki Aydin ( $\square$ zekiaydindr@yahoo.com )

Darica Farabi Training and Research Hospital

Murvet Yilmaz

Bakırköy Dr.Sadi Konuk Eğitim ve Araştırma Hastanesi

Murat Sipahioglu

Erciyes Üniversitesi Tıp Fakültesi Hastaneleri

Erkan Dervisoglu

Kocaeli Üniversitesi Araştırma ve Uygulama Hastanesi

Nihal Aydemir

Ankara Numune Eğitim ve Araştırma Hastanesi

Sami Uzun

Haseki Eğitim ve Araştırma Hastanesi

Zulal Istemihan

Istanbul University

Oktay Unsal

Uludağ University

Erhan Tatar

Izmir Bozyaka Eğitim ve Araştırma Hastanesi

Haci Bayram Berktas

Inonu University

Arzu Ozdemir

Bakırköy Dr.Sadi Konuk Eğitim ve Araştırma Hastanesi

Abdullah Sumnu

Istanbul Medipol University

Gizem Kumru

Ankara University

Hakki Cetinkaya

Sultan Abdülhamid Han Training and Research Hospital

Sinan Kazan

Afyon Kocatepe University 


\section{Ismail Kocyigit}

Erciyes Üniversitesi Tıp Fakültesi Hastaneleri

\section{Cenk Gokalp}

Trakya University

\section{Baris Hasbal}

Şişli Etfal Eğitim ve Araştırma Hastanesi

\section{Ayse Serra Artan}

Bezmiâlem Vakıf Üniversitesi

\section{Ruya Ozelsancak}

Cukurova University

\section{Dilek Taymez}

Kocaeli State Hospital

\section{Serap Yadigar}

Dr Lütfı Kırdar Kartal Eğitim ve Araştırma Hastanesi

\section{Selma Alagoz}

Istanbul University Cerrahpaşa

\section{Bilal Burcak Aslan}

Bursa Yuksek Ihtisas Egitim Ve Arastirma Hastanesi

\section{Selcuk Yaylaci}

Sakarya University

Jabrayil Jabrayilov

Hacettepe University

\section{Kenan Turgutalp}

Mersin University

\section{Belda Dursun}

Pamukkale University

\section{Garip Sahin}

\section{Eskişehir Osmangazi University}

\section{Research Article}

Keywords: Primary glomerular diseases, Minimal change disease, Nephrotic syndrome

Posted Date: January 25th, 2022

DOI: https://doi.org/10.21203/rs.3.rs-1221382/v1

License: (c) (i) This work is licensed under a Creative Commons Attribution 4.0 International License. Read Full License 


\section{Abstract}

Background: In our study, diagnostic and demographic characteristics of patients diagnosed with minimal change disease (MCD) by biopsy, clinical and laboratory findings in our country were investigated.

Methods: Data were obtained from the Turkish Society of Nephrology Glomerular Diseases (TSN-GOLD) Working Group database. Demographic characteristics, indications for biopsy, diagnosis of the glomerular diseases, comorbidities, laboratory and biopsy findings of all patients were recorded. The data presented is cross-sectional and includes application data for the biopsy period.

Results: Of 3875 patients, 233 patients with MCD (median age 35.0 years) were included in the study, which constitutes $6.0 \%$ of the total glomerulonephritis database. Renal biopsy was performed in 196 (84.1\%) patients due to nephrotic syndrome. Median serum creatinine was $0.7(0.6-1.0) \mathrm{mg} / \mathrm{dl}$, mean eGFR was $104 \pm 33 \mathrm{ml} / \mathrm{min} / 1.73 \mathrm{~m} 2$ and median proteinuria $6000 \mathrm{mg} /$ day. The number of patients under the age of 40 years was 139 (59.7\%) (Group A), and the number of patients aged 40 years and over was 94 (40.3\%) (Group B). Compared to Group A, global sclerotic glomeruli (24 vs. 43,p<0.001) interstitial inflammation ( 15 vs. $34, p<0.001$ ), interstitial fibrosis ( 20 vs. $31, p=0.001$, vascular changes ( 10 vs. $25, p<0.001)$ and tubular atrophy ( 18 vs. $30, p<0.001)$ were found to be significantly higher in Group B. There was no difference in immunofluorescent staining properties between the two groups.

Conclusion: Our data are generally compatible with the literature. Chronic histopathological changes were more common in patients aged 40 years and older than younger patients. Studies investigating the effects of these different features on renal survival are needed.

\section{Introduction}

Minimal change disease (MCD) is the leading cause of nephrotic syndrome (about $90 \%$ ) in children. It is less common in adults (approximately 10\%). In MCD, a transient viral respiratory illness is usually followed by rapidly developing nephrotic syndrome (NS). Renal function is usually preserved. The NS often responds well to corticosteroid therapy $(1,2)$. The pathological manifestation of MCD is diffuse effacement of the epithelial foot process. It has also been suggested that MCD is a renal manifestation of some systemic immune abnormalities, particularly dysfunction of T lymphocytes $(1,2)$. MCD is usually a self-limited and relatively benign disease. Spontaneous remission develops with supportive care in $10-75 \%$ of cases (2).

Minimal change disease is characterized by the absence of pathological changes on light microscopy. Immunofluorescence is negative for immunoglobulins and complement except in rare instances $(3,4)$.

Minimal change disease accounts for a smaller proportion of cases of nephrotic syndrome in adults. Epidemiological data obtained from large national biopsy registries have shown that the prevalence of MCD varies from 10 to $15 \%$ of all kidney biopsies (5). The percentage of nephrotic adults with MCD has 
since decreased; by contrast, the proportion of nephrotic adults with FSGS has increased (5). It is unknown whether the features and course of the disease are the same in differing parts of the world. In this regard, we aimed to investigate demographic, clinical and laboratory characteristics of adult patients diagnosed with MCD from the registry database of the Turkish Society of Nephrology Glomerular Diseases Working Group.

\section{Material And Methods}

\section{Patients' Characteristics}

This study is a retrospective study between 2009-2019 on the epidemiologic data of patients who underwent native kidney biopsy and were diagnosed as 'primary glomerular disease' extracted from the 'Primary Glomerulonephritis Registry of Turkish Society of Nephrology' database. From May 2009 till May 2019, 4399 patients from 47 Nephrology Centers all over Turkey were evaluated. After excluding 524 patients with missing baseline data, light microscopy and immunofluorescence microscopy findings, 3875 patients with complete data were analyzed. (6). Patients diagnosed with MCD from this database were included in our study.

Patients aged 18 years or more with documented biopsy findings were included in the study. Kidney biopsies were performed in all patients with a normal kidney size who presented with active urinary sediment, proteinuria and decreased glomerular filtration rate (GFR). The kidney biopsies were performed percutaneously using an automated gun guided by ultrasound (7).

All the cases included were classified as primary glomerular disease, since one of the exclusion criteria was another disease that could be the cause of glomerulopathy. No algorithm or special workup is requested to exclude secondary reasons of glomerulonephritis, and local routine practice was applied. The patients' data collected include age, gender, body mass index (BMI), blood pressure and laboratory parameters including hemogram, lipid profile, renal function tests, albumin, total protein, 24-hour proteinuria, glucose, uric acid, calcium, alanine aminotransferase (ALT), erythrocyte sedimentation rate (ESR) and light microscopic findings including tubular atrophy, interstitial fibrosis, number of total glomeruli, and number of sclerotic glomeruli; immunofluorescence findings such as immunoglobulin (Ig)G, IgA, IgM, kappa, lambda, fibrinogen, C3 and C1q, serology for human immunodeficiency virus and hepatitis $C$ virus and hepatitis $B$ surface antigen; an autoimmune panel including complement levels (C3 and C4 levels), anti-nuclear antibody (ANA), and anti-double-stranded DNA antibody (anti-dsDNA Ab). Patients with IgM nephropathy and strongly positive immunofluorescent staining who could suspect C1q nephropathy were excluded.

Demographic parameters of all patients, presence of chronic diseases such as hypertension and diabetes mellitus before kidney biopsy, kidney biopsy indication, biopsy date, clinic where biopsy was performed, clinician's clinical diagnosis, pathological diagnosis, drugs used by patients and detailed description of pathological findings were recorded in the database (8). Indications for biopsy were grouped as nephrotic syndrome, nephritic syndrome including rapidly progressive glomerulonephritis, mixed nephrotic 
syndrome and asymptomatic urinary abnormalities (AUA). The estimated glomerular filtration rate was calculated with the CKD-EPI formula (9).

\section{Definitions}

Histological findings of MCD were the absence of electron-dense deposits or thickening of the glomerular basement membranes, the absence of negative immunofluorescent staining (or mild staining for $\mathrm{C} 3$ and/or $\lg M)$, and the absence of segmental sclerosis $(3,4)$. Nephrotic syndrome was defined as proteinuria of more than $3.5 \mathrm{~g} /$ day associated with edema, hypoalbuminemia and hyperlipidemia. Nephritic syndrome was defined as proteinuria less than $3.5 \mathrm{~g} /$ day associated with hematuria, hypertension and slowly progressive renal failure. Mixed nephrotic syndrome was defined as nephrotic syndrome together with findings of nephritic syndrome. Proteinuria less than $3.5 \mathrm{~g} / \mathrm{day}$ and/or isolated microscopic hematuria were recorded as AUA. No limitation was applied to the methods of laboratory investigations, and all parameters were measured with the available local techniques (7).

\section{Statistical Analyses}

Statistical analyses were performed using. IBM SPSS Statistics for Windows (Version 22.0. Armonk, NY: IBM Corp.) software. Numerical variables that exhibited normal distribution were given as mean \pm standard deviation, whereas those having non-parametric data as median and interquartile range (IQR); the categorical variables as frequency and percentage. Of numerical variables with normal distribution, for two-group comparisons student t-test was used. Of numerical variables with abnormal distribution, for two-group comparisons Mann-Whitney $U$ test was used. The Chi-Square statistic was used for testing relationships between categorical variables. For all statistical analyses, P-value $<0.05$ was considered to be statistically significant.

\section{Results}

The baseline characteristics and demographic parameters of the patients with MCD were shown in Table 1. Of the total 3875 patients who were biopsied for various renal abnormalities, 233 (6.0\%) patients [median age (IQR) 35.0 (26.0-50.5) years] were diagnosed as MCD. Of 233 patients, 108 (46.4\%) were female. Hypertension was present in 59 patients $(25.3 \%)$ and diabetes mellitus was present in 6 patients (2.6\%) before kidney biopsy. All patients with hypertension were using angiotensin-converting enzyme inhibitors or angiotensin receptor blocker drugs. All diabetic patients were using metformin, and 3 of them were using dapagliflozin. Nephrologists performed $70.8 \%$ of the patients' biopsies and $29.2 \%$ of them were performed by radiologists. According to the clinical presentation at the time of presentation, 196 (84.1\%) patients had nephrotic syndrome, 7 (3.0\%) patients had nephritic syndrome, 4 (1.7\%) patients had mixed nephrotic and nephritic syndrome and 26 (11.2\%) patients had asymptomatic urine abnormalities. Figure 1 shows the initial diagnosis before the kidney biopsy. In urinalysis, $\geq 5$ leukocyte counts were found in 29 (12.4\%) patients and $\geq 5$ erythrocyte counts and erythrocyte cast in 45 (19.3\%) patients. 
Table 1

Demographic, laboratory and urinary histopathological characteristics of the patients according to age groups.

\begin{tabular}{|c|c|c|c|c|}
\hline n (\%) & $\begin{array}{l}\text { Total } \\
\text { n:233 (100\%) }\end{array}$ & $\begin{array}{l}\text { Group A } \\
\text { (<40 years) } \\
\text { n: } 139(59.7 \%)\end{array}$ & $\begin{array}{l}\text { Group B } \\
\text { ( } \geq 40 \text { years) } \\
\text { n:94 (40.3\%) }\end{array}$ & $p$ \\
\hline \multicolumn{5}{|l|}{ Demographical data } \\
\hline Age (years)* & $\begin{array}{l}35.0(26.0- \\
50.5)\end{array}$ & $28.2 \pm 6.1$ & $55.7 \pm 10.5$ & $<0.001$ \\
\hline Body mass index (kg/m2) & $25.4 \pm 3.7$ & $24.8 \pm 3.8$ & $26.4 \pm 3.2$ & 0.142 \\
\hline Systolic blood pressure (mmHg) & $123 \pm 15$ & $120 \pm 13$ & $127 \pm 17$ & 0.007 \\
\hline Diastolic blood pressure $(\mathrm{mmHg})$ & $76 \pm 9$ & $75 \pm 9$ & $79 \pm 9$ & 0.527 \\
\hline $\begin{array}{l}\text { Biopsy indication as nephrotic } \\
\text { syndrome, } \mathrm{n}(\%)\end{array}$ & $196(84.1 \%)$ & $119(85.6 \%)$ & 77 (81.9\%) & 0.400 \\
\hline \multicolumn{5}{|l|}{ Biochemical data } \\
\hline Glucose (mg/dl) & $95 \pm 21$ & $91 \pm 16$ & $100 \pm 25$ & 0.010 \\
\hline Blood urea nitrogen $(\mathrm{mg} / \mathrm{dl})^{\star}$ & $29(21-43)$ & $25(19-38)$ & $34(25-52)$ & $<0.001$ \\
\hline Creatinine $(\mathrm{mg} / \mathrm{dl})^{*}$ & $0.7(0.6-1.0)$ & $0.7(0.6-0.8)$ & $0.8(0.6-1.2)$ & $<0.001$ \\
\hline GFR (CKD-EPI) (ml/min/1.73m²) & $104 \pm 33$ & $119 \pm 25$ & $83 \pm 33$ & $<0.001$ \\
\hline Uric acid (mg/dl) & $5.8 \pm 1.8$ & $5.6 \pm 1.7$ & $6.2 \pm 1.8$ & 0.259 \\
\hline Calcium (mg/dl) & $8.4 \pm 0.9$ & $8.4 \pm 0.9$ & $8.5 \pm 0.8$ & 0.989 \\
\hline Total protein (gr/dl) & $5.1 \pm 1.2$ & $4.9 \pm 1.2$ & $5.4 \pm 1.2$ & 0.827 \\
\hline Albumin (gr/dl) & $2.6 \pm 1.0$ & $2.5 \pm 1.0$ & $2.7 \pm 0.9$ & 0.556 \\
\hline Total cholesterol (mg/dl) & $350 \pm 139$ & $364 \pm 137$ & $331 \pm 140$ & 0.888 \\
\hline Triglyceride $(\mathrm{mg} / \mathrm{dl})^{\star}$ & $203(126-301)$ & 205 (126-294) & $187(126-308)$ & 0.810 \\
\hline HDL cholesterol $(\mathrm{mg} / \mathrm{dl})^{\star}$ & $56(43-75)$ & $58(44-75)$ & $55(43-77)$ & 0.758 \\
\hline LDL cholesterol $(\mathrm{mg} / \mathrm{dl})^{\star}$ & $226(151-306)$ & $236(160-324)$ & $195(139-275)$ & 0.081 \\
\hline $\operatorname{ALT}(U / I)$ * & $19(14-27)$ & $20(14-28)$ & $17(14-26)$ & 0.098 \\
\hline $\operatorname{ESR}(\mathrm{mm} / \mathrm{h})$ * & $44(21-65)$ & $40(20-62)$ & $47(26-72)$ & 0.188 \\
\hline \multicolumn{5}{|l|}{ *Median and interquartile range, } \\
\hline $\begin{array}{l}\text { GFR; glomerular filtration rate, HDL } \\
\text { aminotransferase, ESR: erythrocyt }\end{array}$ & $\begin{array}{l}\text {-density lipoprot } \\
\text { mentation rate, }\end{array}$ & ר, LDL; low-der & lipoprotein $A L$ & alanine \\
\hline
\end{tabular}




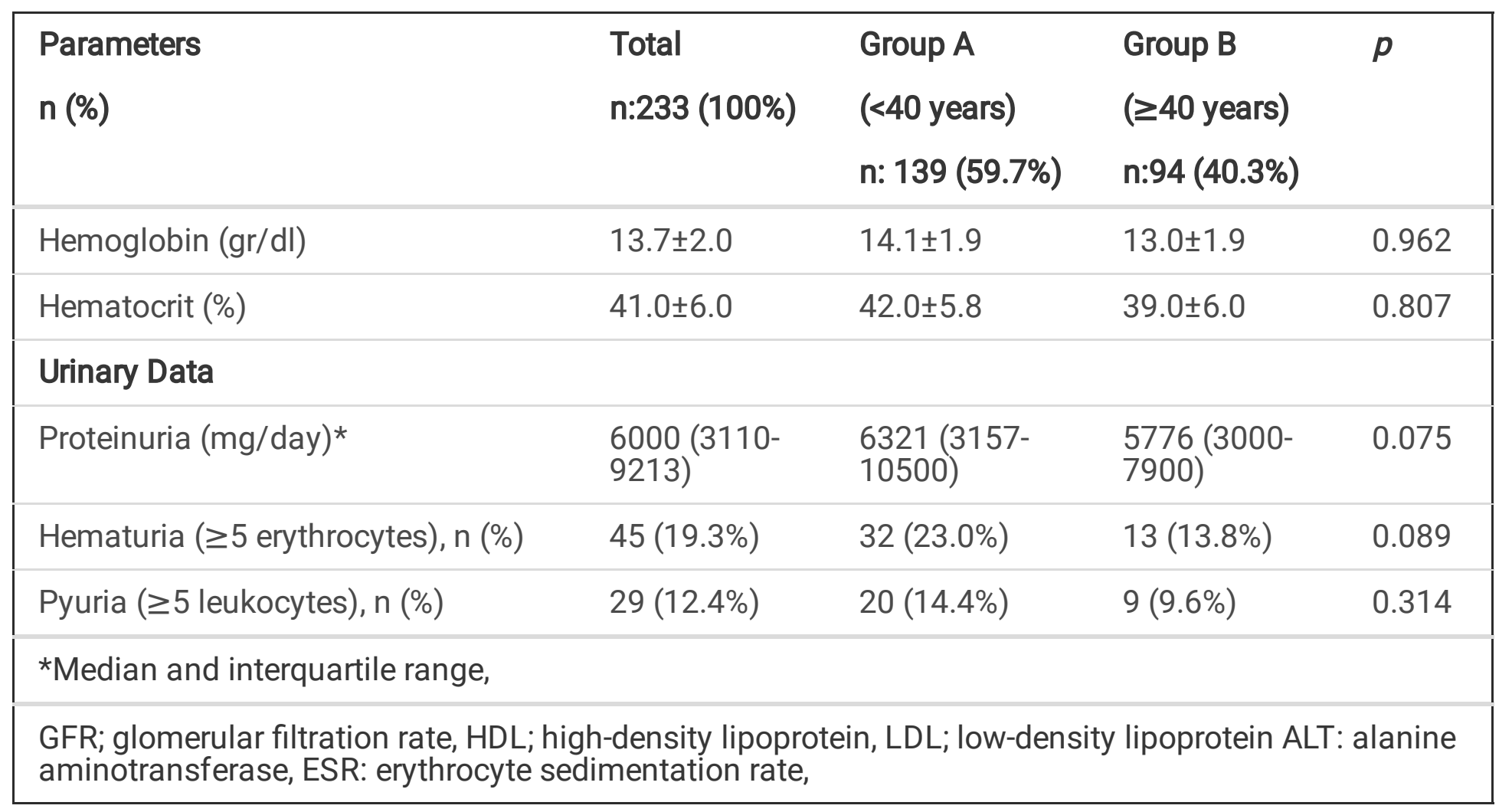

Median serum creatinine was $0.7 \mathrm{mg} / \mathrm{dL}$ (IQR:0.6-1.0), mean estimated glomeruler filtration rate (eGFR) was $104 \pm 33 \mathrm{ml} / \mathrm{min} / 1.73 \mathrm{~m} 2$ and median 24-hour proteinuria was $6000 \mathrm{mg} /$ day (IQR:3110-9213) of total MCD patients.

The number of patients under the age of 40 years was 139 (59.7\%) (Group A), and the number of patients aged 40 years and over was 94 (40.3\%) (Group B). Compared to Group A (<40 years), systolic blood pressure ( $120 \pm 13$ vs. $127 \pm 17, p=0.007)$, glucose ( $91 \pm 16$ vs. $100 \pm 25, p=0.01)$, urea [25 (19-38) vs. 34 (25$52), p<0.001]$ and creatinine [0.7 (0.6-0.8) vs. $0.8(0.6-1.2), p<0.001)$ were found to be significantly higher in Group $B(\geq 40$ years). eGFR ( $119 \pm 25$ vs. $83 \pm 33, p<0.001)$ and total glomeruli count $(17.0$ (11.0-25.0) vs. 14.5 (8.0-24.0), $p=0.035$ ) were found to be low in Group B (Table 1). There were no differences between two groups in terms of BMI, diastolic blood pressure (DBP), serum uric acid, calcium, total protein, albumin, proteinuria, total cholesterol, triglyceride, HDL cholesterol, LDL cholesterol, ALT, ESR, hemoglobin and hematocrit levels (Table 1).

According to renal biopsy results, the median number of total glomeruli was 17.0 (10.0-25.0) (Table 2). Global sclerotic glomeruli were detected in 67 (28.7\%) of the patients. Mesangial proliferation, basement membrane thickening, interstitial inflammation, interstitial fibrosis, vascular changes and tubular atrophy were detected in 65 (27.9), 15 (6.4\%), 49 (21.0), 51 (21.9\%), 35 (15\%) and 48 (20.6) patients, respectively. 
Table 2

Histopathological and immunofluorescence microscopy characteristics of the patients according to age groups.

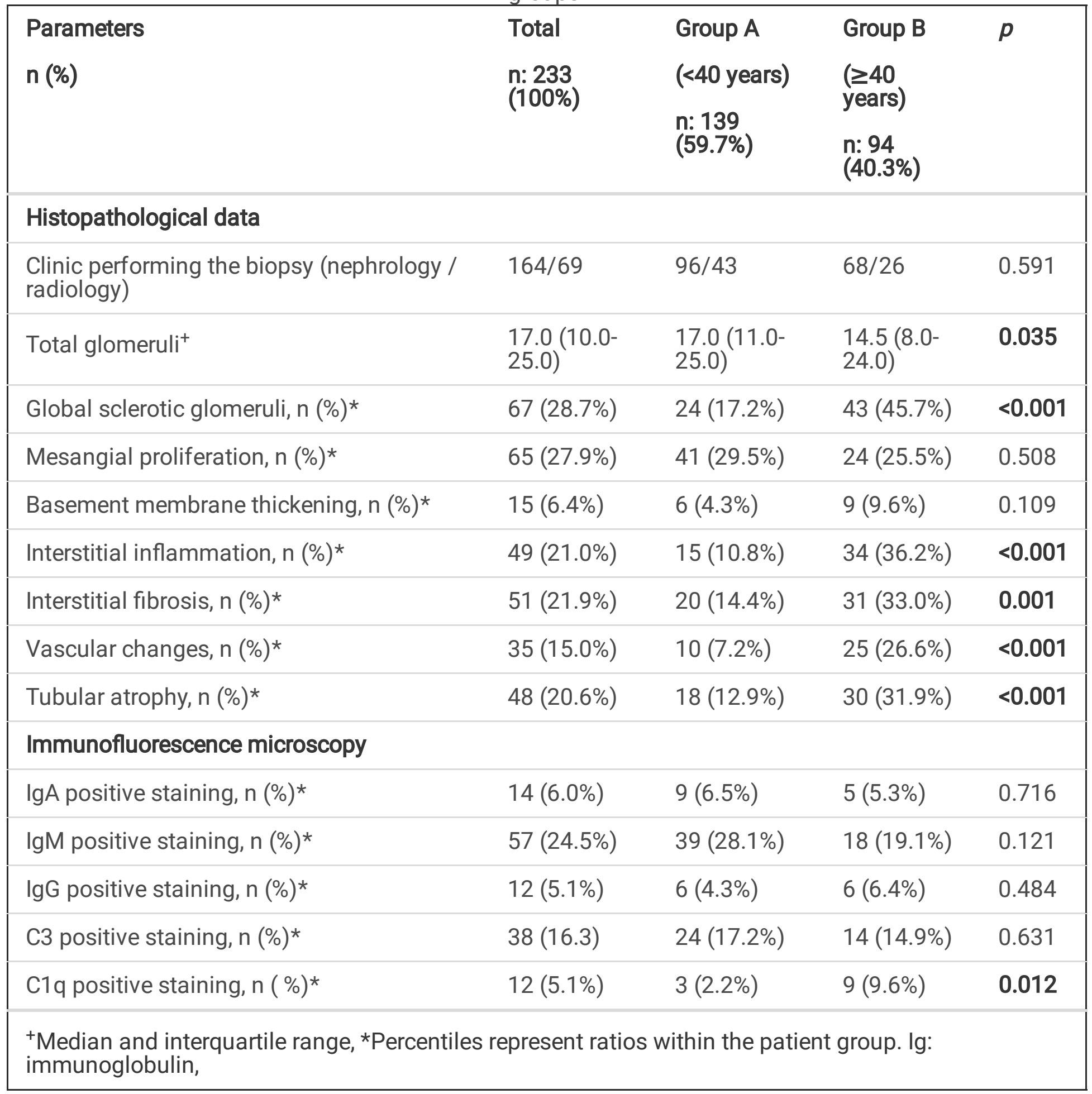

In immunofluorescence microscopy, IgA, IgM, IgG, C3 and C1q staining were detected in 14, 57, 12, 38 and 12 patients, respectively. When Group A and Group B were compared, no difference was found between immunofluorescent staining properties (Table 2). 
Compared to Group A (<40 years), global sclerotic glomeruli ( 24 vs. $43, p<0.001)$, interstitial inflammation ( 15 vs. $34, p<0.001)$, interstitial fibrosis ( 20 vs. $31, p=0.001$, vascular changes $(10$ vs. $25, p<0.001)$ and tubular atrophy ( 18 vs. $30, p<0.001)$ were found to be significantly higher in Group $B(40 \geq$ years). There was no difference between the two groups in terms of mesangial proliferation ( 41 vs. $24, p=0.508)$ and basement membrane thickening ( 6 vs. $9, p=0.109$ ) (Table 2).

\section{Discussion}

This multicenter observational study is the first and the most comprehensive one regarding the epidemiologic data of patients with MCD in Turkey. Adult-onset MCD comprised 6\% (233/3875) of the entire primary glomerulonephritis database. The median age was 35.0 (26.0-50.5) years, and $59.7 \%$ were under 40 years of age. Renal biopsy was performed in 196 (84.1\%) patients due to nephrotic syndrome. Compared to the group under 40 years of age, chronic changes were more common in the group aged $\geq 40$ years.

In minimal change disease, the glomeruli are pathologically normal in the light microscope and there are no complement or immunoglobulin deposits in the immunofluorescent microscope. The characteristic histological lesion that can only be seen on electron microscopy is diffuse effacement of epithelial foot processes. There are three other disorders that usually present with the nephrotic syndrome and that may show only minor changes on light microscopy: idiopathic mesangial proliferative glomerulonephritis, immunoglobulin M (IgM) nephropathy, and C1q nephropathy. These disorders may represent variants of MCD or FSGS $(3,4.10)$

The frequency of MCD among primary glomerulonephritis in adults was determined as $9.1 \%$ in the study by Malafronte et al. (11), and $0.9 \%$ in Li et al. (12). In our study, it was found to be $6.0 \%$.

In a retrospective analysis of 95 adult patients with $M C D$, at presentation, Waldman et al. (13) found a median age 45 years, serum creatinine $1.4 \mathrm{mg} / \mathrm{dl}$, eGFR $72 \mathrm{~mL} / \mathrm{min} / 1.73 \mathrm{~m} 2$, proteinuria $9.9 \mathrm{~g} /$ day, hematuria $29 \%$, serum albumin $2.2 \mathrm{~g} /$ day, serum cholesterol $421 \mathrm{mg} / \mathrm{dL}$ and hypertension $43 \%$. Huang et al. (14) evaluated 46 Chinese patients diagnosed with adult MCD by biopsy in their retrospective study. The male to female ratio was 1.2:1. The mean age of onset was 30.9 years, and $80 \%$ of the patients with MCD were less than 40 years. The mean daily proteinuria was $10.2 \mathrm{~g}$, and serum albumin was $1.8 \mathrm{mg} / \mathrm{dl}$. Azotemia occurred in 16 (35\%) of 46 cases; hypertension, $13 \%$; and microscopic hematuria, $13 \%$. In another study, the male to female ratio was found to be 1:1.4, with a mean age of 37 years. At presentation, hypertension was found in $47 \%$ of patients, microscopic haematuria in $33 \%$, hypercholesterolemia and hypertriglyceridemia in $96 \%$ (15). In a study conducted in England, 89 patients were examined, the mean age was 42 , the male-female ratio was $1.28: 1$, the average albumin was 2.0 $\mathrm{g} / \mathrm{dl}$, nephrotic syndrome was found in $73 \%$, and microscopic hematuria was found in $28.3 \%$. Hematuria was more frequent in patients aged more than 45 (13 of 32) than in younger patients $(7$ of 41$)(P<0.05)$ (16). In our study, the median age of the patients was 35.0 (26.0-50.5) years, creatinine 0.7 (0.6-1.0) $\mathrm{mg} / \mathrm{dl}$, proteinuria 6000 (3110-9213) g/day, triglyceride 203 (126-301) mg/dl, mean serum cholesterol 
$350 \pm 139 \mathrm{mg} / \mathrm{dl}$ and albumin $2.6 \pm 1.0 \mathrm{~g} / \mathrm{dl}$ detected. Hypertension was found in $25.3 \%$ of the patients and hematuria in $19.3 \%$ of the patients. The male to female ratio was $1.16: 1.59 .7 \%$ of our patients were under the age of 40 . The eGFR of $30(12.9 \%)$ patients was below $60 \mathrm{ml} / \mathrm{min} / 1.73 \mathrm{~m}^{2}$. Nephrotic syndrome was found in $84.1 \%$ of the patients and microscopic hematuria was found in $19.3 \%$ of the patients. There was no difference between age groups in terms of proteinuria level and microscopic hematuria.

Tse et al. (17) evaluated 50 adult MCDs in their study, and the mean age was $48.3 \pm 18.1$ years, and the patients were divided into two groups as under 50 years old and over. Serum creatinine was found to be high $((p=0.007))$ and creatinine clearance was found to be significantly lower $(p=0.003)$ in the 50 years and older group. In our study, creatinine was found to be higher $(0.8 \mathrm{vs} .0 .7 \mathrm{mg} / \mathrm{dl}, \mathrm{p}<0.001)$ and eGFR was significantly lower ( $83 \mathrm{vs.} 119 \mathrm{ml} / \mathrm{min} / 1.73 \mathrm{~m}^{2}, \mathrm{p}<0.001$ ) in the $\geq 40$ age group compared to the $<40$ year-old group.

There are some racial differences in the prevalence and prognosis of idiopathic nephrotic syndrome. The Asian adult-onset MCD had younger age and male predominance in comparison to those of the Western population (14). In our study, the number of men was higher, and the median age of onset of disease was 35 years, and it was between the Western and Asian populations.

In a study performed in Japan, 62 adults MCDs were evaluated. All renal biopsy specimens contained an average of $19.8 \pm 1.3$ glomeruli/specimen. Global sclerosis was detected in $14(22.6 \%)$ of the patients, and mesangial hypercellularity was found in $35(56.4 \%)$ patients. Weakly positive immunofluorescence (IgG or IgM) was found in 19 (30.6\%) patients (18). Similarly, in our study, the median glomeruli count was 17.0 (10.0-25.0). Global sclerosis was detected in 67 (28.7\%) of the patients, and mesangial hypercellularity was found in $65(27.9 \%)$ patients. Similarly, weak positive immunofluorescence (IgG or $\operatorname{lgM})$ was found in $67(28.7 \%)$ patients.

Histologically, MCD is characterized by normal-appearing glomeruli by light microscopy and the absence of complement or immunoglobulin deposits by immunofluorescence microscopy $(3,4)$. In our study, in immunofluorescence microscopy, IgA, IgM, IgG, C3 and C1q staining were detected in 14 (6.0\%), 57 (24.5\%), 12 (5.1\%), 38 (16.3\%) and $12(5.1 \%)$ patients, respectively. There was no difference in immunofluorescence staining between the groups below and above 40 years of age. Compared to the group under 40 years of age, chronic changes were more common in the group aged 40 and over. Global sclerotic glomeruli ( $17.2 \%$ vs. $45.7 \%)$, interstitial fibrosis ( $14.4 \%$ vs. $33.0 \%)$, vascular changes $(7.2 \%$ vs. $26.6 \%)$, tubular atrophy ( $12.9 \%$ vs. $31.9 \%)$ were more common in patients $\geq 40$ years of age.

IgM deposits may be found in patients with MCD, focal segmental glomerulosclerosis (FSGS), and mesangial proliferative glomerulonephritis. Some experts, however, believe that IgM nephropathy is a distinct entity characterized by mesangial proliferation and prominent mesangial deposits of IgM and complement. Debate remains as to the clinical significance of IgM deposition in glomerular disease (11). In our study, in immunofluorescence microscopy, IgM staining (weak) was detected in 57 (24.5\%) patients. There were no clinical and laboratory differences in IgM positive patients. 
Our study had some limitations. First, our study did not reveal data regarding the prognosis of patients with adult-onset MCD. Second, because biopsies are analyzed by different pathologists, the data may not be completely homogeneous. In addition, an electron microscopic examination was not performed in all cases, and, hence, it was not presented in the manuscript. However, the data presented by the Turkish Society of Nephrology Glomerular Diseases Study Group represent the histological findings in patients with MCD, despite differing interpretations among different pathologists and different biopsy policies and histopathological findings. Our database, which includes a large number of kidney biopsies, presents important findings considering our geographical location.

\section{Conclusion}

This is the first report by the TSN-GOLD Study Group of patients with adult-onset MCD from the National Renal Biopsy Registry in Turkey. Chronic histopathological changes were more common in patients aged 40 years and older than younger patients, and there was no difference in immunofluorescence staining characteristics. Studies investigating the effects of these different features on renal survival are needed.

\section{Declarations}

\section{Ethics approval and consent to participate:}

The present study was approved by the Ethical Committee of the Istanbul Medical Faculty of Istanbul University. Informed consent was obtained from all individual participants included in the study. All procedures performed in studies involving human participants were in accordance with the ethical standards of the institutional and/or national research committee at which the studies were conducted (IRB approval number 1164/2011) and with the 1964 Helsinki Declaration and its later amendments or comparable ethical standards.

\section{Consent for publish:}

All authors declare that they give consent for publication. This manuscript does not contain any information/images that could identify the participants.

\section{Availability of data and materials:}

All data and materials are registered at the Turkish Society of Nephrology Glomerular Diseases Working Group (TSN-GOLD) website (http://pgh.tsn.org.tr). All data generated or analysed during this study are included in this published article.

\section{Competing interests:}

The authors have declared that no conflict of interest exists.

\section{Funding:}


None

\section{Authors' contributions:}

All authors contributed to the study conception and design. All authors contributed to study material preparation, data collection. Analysis; Zeki Aydin, Murvet Yilmaz. The first draft of the manuscript was written by Zeki Aydin and Garip Sahin. All authors commented on previous versions of the manuscript. All authors read and approved the final manuscript.

\section{Acknowledgements:}

We would like to express our endless thanks to the Turkish Society of Nephrology, who organized the background of the study, and to the pathologists in each center for their contributions to patient care and their help in providing these data.

\section{References}

1. Stefan G, Busuioc R, Stancu S, Hoinoiu M, Zugravu A, Petre N, et al. Adult-onset minimal change disease: the significance of histological chronic changes for clinical presentation and outcome. Clin Exp Nephrol. 2021 Mar;25(3):240-50. doi: 10.1007/s10157-020-01985-7.

2. Vivarelli M, Massella L, Ruggiero B, Emma F. Minimal change disease. Clin J Am Soc Nephrol. 2017;12(2):332-45. doi: 10.2215/CJN.05000516.

3. Fogo A, Hawkins EP, Berry PL, Glick AD, Chiang ML, MacDonell RC Jr, et al. Glomerular hypertrophy in minimal change disease predicts subsequent progression to focal glomerular sclerosis. Kidney Int 1990; 38:115-23. doi: 10.1038/ki.1990.175.

4. Shirato I. Podocyte process effacement in vivo. Microsc Res Tech 2002; 57:241-6. doi: 10.1002/jemt.10082.

5. Fiorentino M, Bolignano D, Tesar V, Pisano A, Van Biesen W, D'Arrigo G, et al; ERA-EDTA Immunonephrology Working Group. Renal Biopsy in 2015--From Epidemiology to Evidence-Based Indications. Am J Nephrol. 2016;43(1):1-19. doi: 10.1159/000444026.

6. Turkmen A, Sumnu A, Cebeci E, Yazici H, Eren N, Seyahi N, et al. Epidemiological features of primary glomerular disease in Turkey: a multicenter study by the Turkish Society of Nephrology Glomerular Diseases Working Group. BMC Nephrol. 2020 Nov 14;21(1):481. doi: 10.1186/s12882-020-02134-8.

7. Aydin Z, Turkmen K, Dede F, Yasar E, Ozturk S, Aydin M, et al. Demographic, clinical and laboratory characteristics of rapidly progressive glomerulonephritis in Turkey: Turkish Society of NephrologyGlomerular Diseases (TSN-GOLD) Working Group. Clin Exp Nephrol. 2021;25(2):173-83. doi: 10.1007/s10157-020-01978-6.

8. Ozturk S, Sumnu A, Seyahi N, Gullulu M, Sipahioglu M, Artan S, et al. Demographic and clinical characteristics of primary glomerular diseases in Turkey. Int Urol Nephrol 2014;46:2347-55. doi: 10.1007/s11255-014-0838-3. 
9. Levey AS, Stevens LA, Schmid CH, Zhang YL, Castro AF 3rd, Feldman HI, et al; CKD-EPI (Chronic Kidney Disease Epidemiology Collaboration). (2009) A new equation to estimate glomerular filtration rate. Ann Intern Med 150:604-12. doi: 10.7326/0003-4819-150-9-200905050-00006.

10. Panzer SE, Laskowski J, Renner B, Kulik L, Ljubanovic D, Huber KM, et al. IgM exacerbates glomerular disease progression in complement-induced glomerulopathy. Kidney Int. 2015;88(3):528-37. doi: 10.1038/ki.2015.120.

11. Malafronte P, Mastroianni-Kirsztajn G, Betônico GN, Romão JE Jr, Alves MA, Carvalho MF, et al. Paulista registry of glomerulonephritis: 5-year data report. Nephrol Dial Transplant. 2006; 21: 3098105. doi: 10.1093/ndt/gfl237.

12. Li LS, Liu ZH. Epidemiologic data of renal diseases from a single unit in China: analysis based on 13,519 renal biopsies. Kidney Int. 2004;66(3):920-3. doi: 10.1111/j.1523-1755.2004.00837.x.

13. Waldman M, Crew RJ, Valeri A, Busch J, Stokes B, Markowitz G, et al. Adult minimal-change disease: clinical characteristics, treatment, and outcomes. Clin J Am Soc Nephrol. 2007;2(3):445-53. doi: 10.2215/CJN.03531006.

14. Huang JJ, Hsu SC, Chen FF, Sung JM, Tseng CC, Wang MC. Adult-onset minimal change disease among Taiwanese: clinical features, therapeutic response, and prognosis. Am J Nephrol. 2001;21(1):28-34. doi: 10.1159/000046215.

15. Mak SK, Short CD, Mallick NP. Long-term outcome of adult-onset minimal-change nephropathy. Nephrol Dial Transplant. 1996;11(11):2192-201. doi: 10.1093/oxfordjournals.ndt.a027136.

16. Nolasco F, Cameron JS, Heywood EF, Hicks J, Ogg C, Williams DG. Adult-onset minimal change nephrotic syndrome: a long-term follow-up. Kidney Int. 1986;29(6):1215-23. doi: 10.1038/ki.1986.130.

17. Tse KC, Lam MF, Yip PS, Li FK, Choy BY, Lai KN, et al. Idiopathic minimal change nephrotic syndrome in older adults: steroid responsiveness and pattern of relapses. Nephrol Dial Transplant. 2003;18(7):1316-20. doi: 10.1093/ndt/gfg134.

18. Nakayama M, Katafuchi R, Yanase T, Ikeda K, Tanaka H, Fujimi S. Steroid responsiveness and frequency of relapse in adult-onset minimal change nephrotic syndrome. Am J Kidney Dis. 2002 Mar;39(3):503-12. doi: 10.1053/ajkd.2002.31400.

\section{Figures}




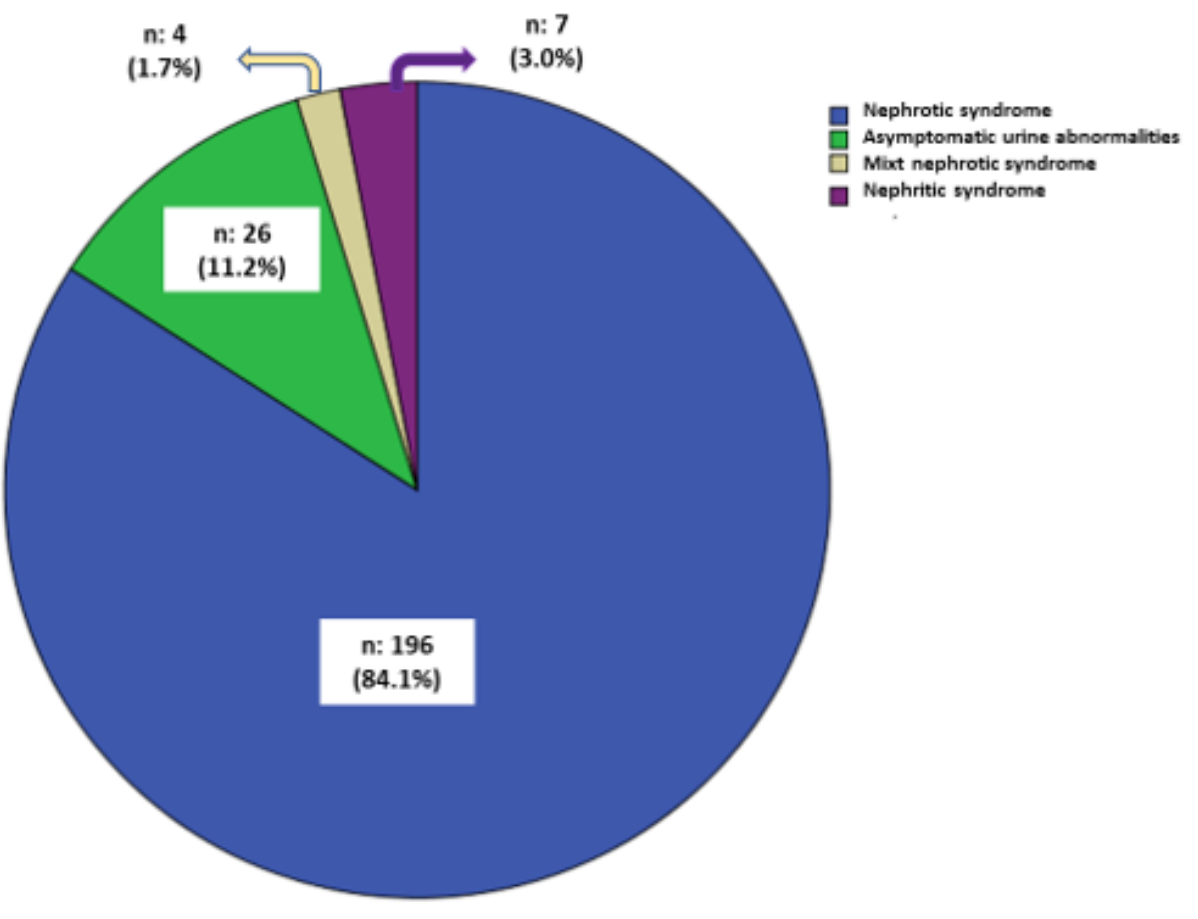

Figure 1

The indications for renal biopsy of minimal change disease 